\title{
Evaluation of Adhesive Behaviors of Chromium Nitride Coating Films Produced by Arc Ion Plating Method*
}

\author{
Ri-ichi MURAKAMI**, Yun-Hae KIM ${ }^{* * *}$, Kazushi KIMURA**, \\ Daisuke YONEKURA** and Do-Hoon SHIN**
}

\begin{abstract}
Scratch tests and pin-on-disk wear tests were performed to clarify the cracking and delaminating behavior of $\mathrm{CrN}$ coatings. The $\mathrm{CrN}$ films were coated onto an aluminum alloy substrate, JIS A2024, by an arc ion plating method. Eight types of single-layered coating and multilayered coatings were prepared by changing the bias voltage during the deposition. $\mathrm{L}_{\mathrm{CI}}$ and $\mathrm{L}_{\mathrm{CII}}$ values were not improved by increasing the number of layers. The critical loads of the single-layered coatings decreased with increasing the bias voltage. It appears that, for the multilayered coatings, the combination of bias voltages influenced the critical loads. The critical loads strongly depended on dynamic hardness and Young's modulus. In particular, the critical loads of the multilayered coatings were influenced by the properties of the intermediate and bottom layers as well as the surface roughness, hardness and Young's modulus of the top layer. The large film delamination for single-layered coatings deposited using a high bias voltage occurred during pin-on-disk wear tests even though the critical loads of the single-layered coatings were higher than those of the multilayered coatings. If the brittle top layer could be broken and delaminated by the sliding contact, the ductile bottom layer coated under a bias voltage of $0 \mathrm{~V}$ could endure the complete delamination of film.
\end{abstract}

Key Words: Scratch Test, Tribology, Aluminum Alloy, Arc Ion Plating, CrN, Thin Film

\section{Introduction}

Aluminum alloy is widely used for various machine parts because of its high specific strength and good workability. Because aluminum alloy also has a low wear resistance, its surface needs to be modified. Usually, the anodic oxidation method is applied to improve the wear resistance of aluminum alloy ${ }^{(1),(2)}$. The anodic oxidation method produces a highly hardened surface, but it is difficult to maintain the dimensional accuracy of the parts because of the marked change in dimensions.

Physical vapor deposition (PVD) methods are used to improve the tribological properties of working tools and machine parts. Because PVD coating is normally performed at $573 \mathrm{~K}$, machine parts are scarcely influenced by the coating heat. TiN, $\mathrm{CrN}$ and diamond like car-

* Received 28th May, 2005 (No. 04-4132)

** Department of Mechanical Engineering, The University of Tokushima, 2-1 Minami-josanjima-cho, Tokushima 7708506, Japan. E-mail: murakami@me.tokushima-u.ac.jp

*** Department of Mechanical and Materials Engineering, Korea Maritime University, 1 Dongsam-dong, Youngdogu, Busan 606-080, Korea bon (DLC) films are coated by PVD coatings. CrN film has a good wear resistance ${ }^{(3),(4)}$, corrosion resistance ${ }^{(5),(6)}$, oxidation properties $^{(7),(8)}$ and thermal stability ${ }^{(9)}$. Many researchers have studied the tribological properties of $\mathrm{CrN}^{(10)-(12)}$. Martinez et al. ${ }^{(10)}$ have reported that for nanometric $\mathrm{CrN} / \mathrm{Cr}$ multilayers, the tribological behavior depends on the film properties, coating-substrate interface and substrate mechanical properties. Lee et al. ${ }^{(11)}$ have predicted the wear life of a TiN coating using the results of indentation, scratch and repeated sliding tests.

In this study, $\mathrm{CrN}$ film has been deposited onto an aluminum alloy substrate under various bias voltages using an arc ion plating method. The influence of the bias voltage on the bonding strength between the $\mathrm{CrN}$ coating and the aluminum alloy substrate has been evaluated by a scratch test and a pin-on-disk wear test. Then the influence of the multilayered coating on the cracking and delamination of the film is discussed.

\section{Experimental Procedure}

The substrate material of the specimens was JIS A2024 T4 aluminum alloy containing HV 151. The chemical compositions of this material are $4.5 \% \mathrm{Cu}, 1.5 \% \mathrm{Mg}$, 
$0.59 \% \mathrm{Mn}, 0.28 \% \mathrm{Fe}, 0.11 \% \mathrm{Si}, 0.02 \% \mathrm{Cr}, 0.02 \% \mathrm{Zn}$, $0.02 \% \mathrm{Ti}$ and $0.02 \% \mathrm{Ti}+\mathrm{Zr}$. The substrate for coating was machined to a disk of $20 \mathrm{~mm}$ diameter and $10 \mathrm{~mm}$ height. Each specimen was mechanically polished using \#150\#1500 emery papers and $0.02 \mu \mathrm{m}$ colloidal silica, and then ultrasonically cleaned in acetone.

CrN film was deposited onto the substrate by the arc ion plating (AIP) method using AIP201 equipment (Kobe Steel Ltd.). For CrN film deposition, the specimen was put into a vacuum chamber, which was hung from a holder using stainless wire during deposition. The distance between the target and the specimen was $100 \mathrm{~mm}$. After the vacuum chamber was evacuated using a vacuum pump to $3.3 \times 10^{-3} \mathrm{~Pa}$, the deposition process was started. Details of the deposition process are as follows: Firstly, the specimen surface is cleaned up by ion bombardment at a bias voltage of $-700 \mathrm{~V}$ for $1 \mathrm{~min}$ with no heating. Then it is cooled in the chamber for $60 \mathrm{~min}$ because the temperature exceeds $373 \mathrm{~K}$ by ion bombardment. It is important during this cooling to maintain the temperature below approximately $473 \mathrm{~K}$, which is the softening temperature of the aluminum alloy. The coating of $\mathrm{CrN}$ film was carried out three times using a Cr target (purity 99.99\%) and nitrogen gas. Negative bias voltage was applied to the substrate during the coating process. The coating conditions were an arc current of $60 \mathrm{~A}$, a nitrogen gas pressure of $3.0 \mathrm{~Pa}$ and a bias voltage of $0-60 \mathrm{~V}$. Each coating process was carried out for $30 \mathrm{~min}$ with subsequent cooling for $120 \mathrm{~min}$. Furthermore, multilayered films of $\mathrm{CrN}$ were produced by changing the bias voltage in each coating. The coating conditions and film thickness are shown in Table 1. For sample Nos. $1-4$, the CrN films were coated under a constant bias voltage. For sample Nos. 5-8, the multilayered CrN films were coated using various bias voltages for each layer. The temperature of the specimen, which was directly measured by a thermocouple attached to a dummy specimen in the vacuum chamber, was below $473 \mathrm{~K}$ during the coating process. Film thickness was measured using a surface profilometer (Vecco Instruments, Dektak ${ }^{3}$ ).

Surface roughness was measured using the surface profilometer. Hardness tests were performed using a Shimadzu dynamic ultra-microhardness tester (DUH201W) with a load of $49 \mathrm{mN}$ and Young's modulus of the film was calculated from the load-unload curve. Scratch testing was performed using a CSEM Revertest scratch tester with a conical-spherical diamond indenter $(50 \mu \mathrm{m}$ radius tip) and critical loads of cracking $\left(\mathrm{L}_{\mathrm{CI}}\right)$ and of partial delamination of the film $\left(\mathrm{L}_{\mathrm{CII}}\right)$ were determined by observation of scratch tracks.

Pin-on-disk wear tests were performed to estimate the tribological properties of the coatings. A bearing steel ball (JIS SUJ2) was selected for a pin $6 \mathrm{~mm}$ in diameter. Wear tests were performed under a sliding velocity of $250 \mathrm{~mm} / \mathrm{sec}$ up to a sliding distance of $5000 \mathrm{~m}$ unless film delamination occurred. The normal applied load was 10 N. Disc mass loss was measured using an electrical balance.

\section{Experimental Results}

\subsection{Scratch test results}

3.1.1 Single-layered coatings The scratch track images of single-layered coatings were observed by optical microscopy. Figure 1 shows features of modes I and

Table 1 Coating conditions

\begin{tabular}{|c|c|c|c|c|c|c|}
\hline $\begin{array}{c}\text { Sample } \\
\text { No. }\end{array}$ & Cathode & $\begin{array}{l}\text { Deposition } \\
\text { pressure }\end{array}$ & $\begin{array}{l}\text { Deposition } \\
\text { time }\end{array}$ & $\begin{array}{c}\text { Arc } \\
\text { current }\end{array}$ & $\begin{array}{l}\text { Total coating } \\
\text { thickness, } \mu \mathrm{m}\end{array}$ & $\begin{array}{l}\text { Bias voltage, } \mathrm{V} \\
\text { (top/intermediate/bottom) }\end{array}$ \\
\hline 1 & \multirow{8}{*}{$\mathrm{Cr}$} & \multirow{8}{*}{ 2.66 Pa } & \multirow{8}{*}{$\begin{array}{c}90 \min \\
(30 \min \times 3)\end{array}$} & \multirow{8}{*}{$40 \mathrm{~A}$} & 7.5 & 0 \\
\hline 2 & & & & & 6.3 & -20 \\
\hline 3 & & & & & 6.2 & -40 \\
\hline 4 & & & & & 6.2 & -60 \\
\hline 5 & & & & & 6.1 & $-20,-40,-60$ \\
\hline 6 & & & & & 6.1 & $-60,-40,-20$ \\
\hline 7 & & & & & 7.0 & $-60,-30, \quad 0$ \\
\hline 8 & & & & & 7.0 & $0,-30,-60$ \\
\hline
\end{tabular}

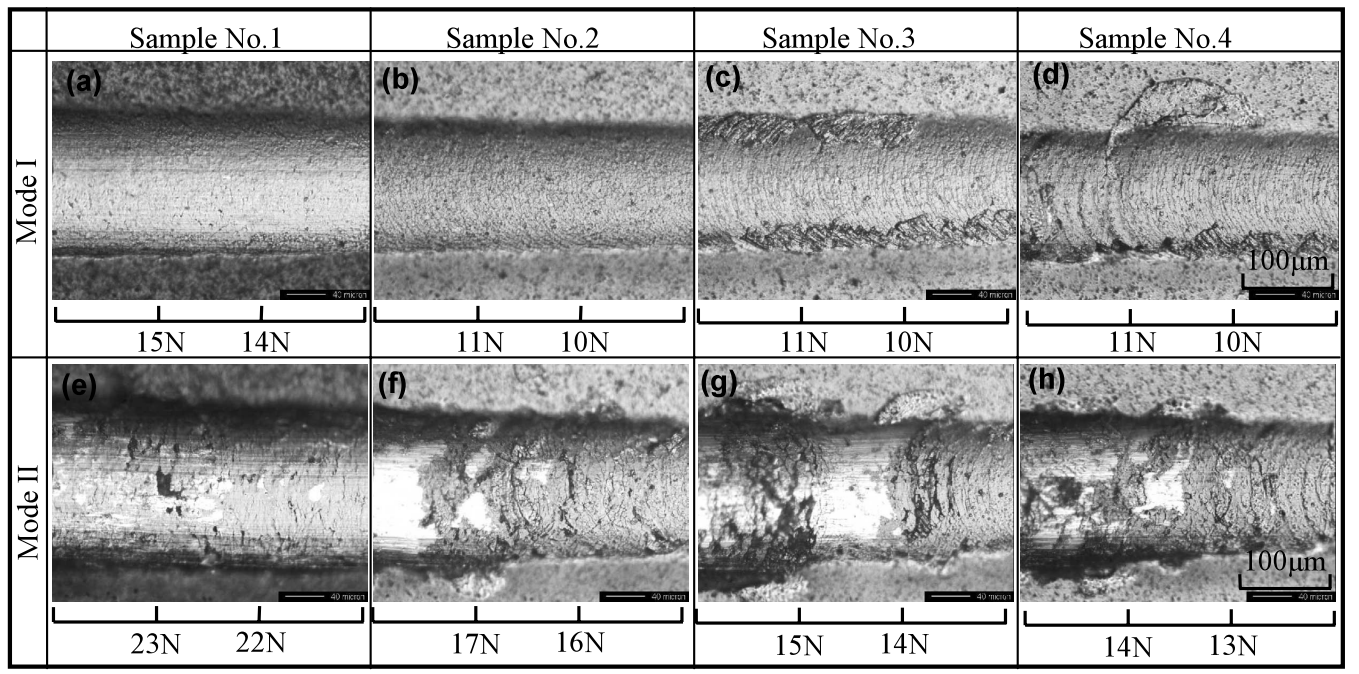

Fig. 1 Optical microscopy images of scratch tracks for single-layered coatings 
II in the scratch track for sample Nos. 1-4. In Fig. 1 (a) and (b), there are no cracks of mode I in the scratch track for sample Nos. 1 and 2 at 10 N. Figure 1 (c) and (d) indicate that, for sample Nos. 3 and 4, many semicircular cracks of mode I are clearly observed at $10 \mathrm{~N}$ in the scratch tracks. For sample Nos. 2-4, there are similar features of film delamination of mode II as shown in Fig. 1 (f) - (h). However, because for sample No. 1, only partial delamination occurs in the scratch track, $\mathrm{L}_{\mathrm{CII}}$ in mode II is higher for sample No. 1 than for the other samples, as shown in Fig. 1 (e).

Critical load was evaluated on the basis of optical microscopy observations. Figure 2 shows the critical load for single-layered coatings and multilayered coatings. In Fig. 2, gray columns indicate the critical load $\left(\mathrm{L}_{\mathrm{CI}}\right)$ for mode I and white columns indicate the critical load $\left(\mathrm{L}_{\mathrm{CII}}\right)$ for mode II. For single-layered coatings, when the bias voltage is low, sample Nos. 1 and 2 exhibit a high $\mathrm{L}_{\mathrm{CI}}$. $\mathrm{L}_{\mathrm{CI}}$ decreases with increasing bias voltage. $\mathrm{L}_{\mathrm{CII}}$, which in-

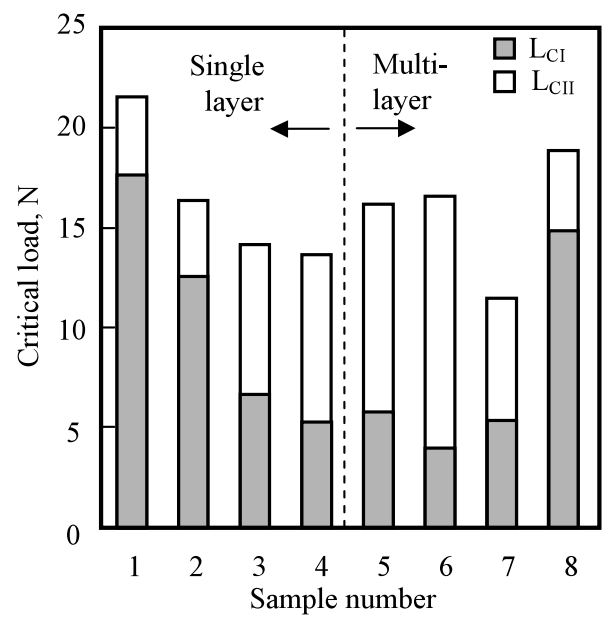

Fig. 2 Critical load data for coatings dicates the partial film delamination load, also decreases with increasing bias voltage.

3.1.2 Multilayered coatings Figure 3 shows features of modes I and II in the scratch track for multilayered coatings. There are different features of scratch tracks between the single-layered coatings and the multilayered coatings. For sample No.5, the collapse of film indicated by mode I is observed on both borders of the scratch track with many cracks. Sample No. 6 shows many cracks of mode I but there is no collapse on both borders. The cracking behavior of mode I for sample No. 7 is quite different from those for sample Nos. 5 and 6. The distance between adjacent cracks for sample No. 7 is approximately $40-50 \mu \mathrm{m}$. This is larger for sample No. 7 than for sample Nos. 5 and 6 in which the crack distance is less than $5 \mu \mathrm{m}$. For sample No. 8, the scratching feature is similar to that of sample No. 1 which was coated under nonbias voltage. The film delaminations of mode II for multilayered coatings are shown in Fig. 3 (e)-(h). These features are similar to those of the single-layered coatings of sample Nos. $2-4$.

Figure 2 shows also the critical loads of scratch tests for multilayered coatings. As shown in Fig. 2, the results sample Nos. 5-7 show that $\mathrm{L}_{\mathrm{CI}}$ and $\mathrm{L}_{\mathrm{CII}}$ values are not improved by increasing the number of layers. However, $\mathrm{L}_{\mathrm{CI}}$ and $\mathrm{L}_{\mathrm{CII}}$ values are higher for sample No. 8 than for sample Nos. 2-4 but these critical loads are still less than that of sample No. 1 (single-layered coating) coated under a nonbias voltage. For 0,30 and $60 \mathrm{~V}$ combinations, the change in bias voltage clearly results in an increase in $\mathrm{L}_{\mathrm{CI}}$. While, the critical loads for 20, 40 and $60 \mathrm{~V}$ combinations are scarcely influenced by coating order.

\subsection{Surface morphology}

3.2.1 Single-layered coatings Figure 4 shows SEM images of all the coating samples and their surface

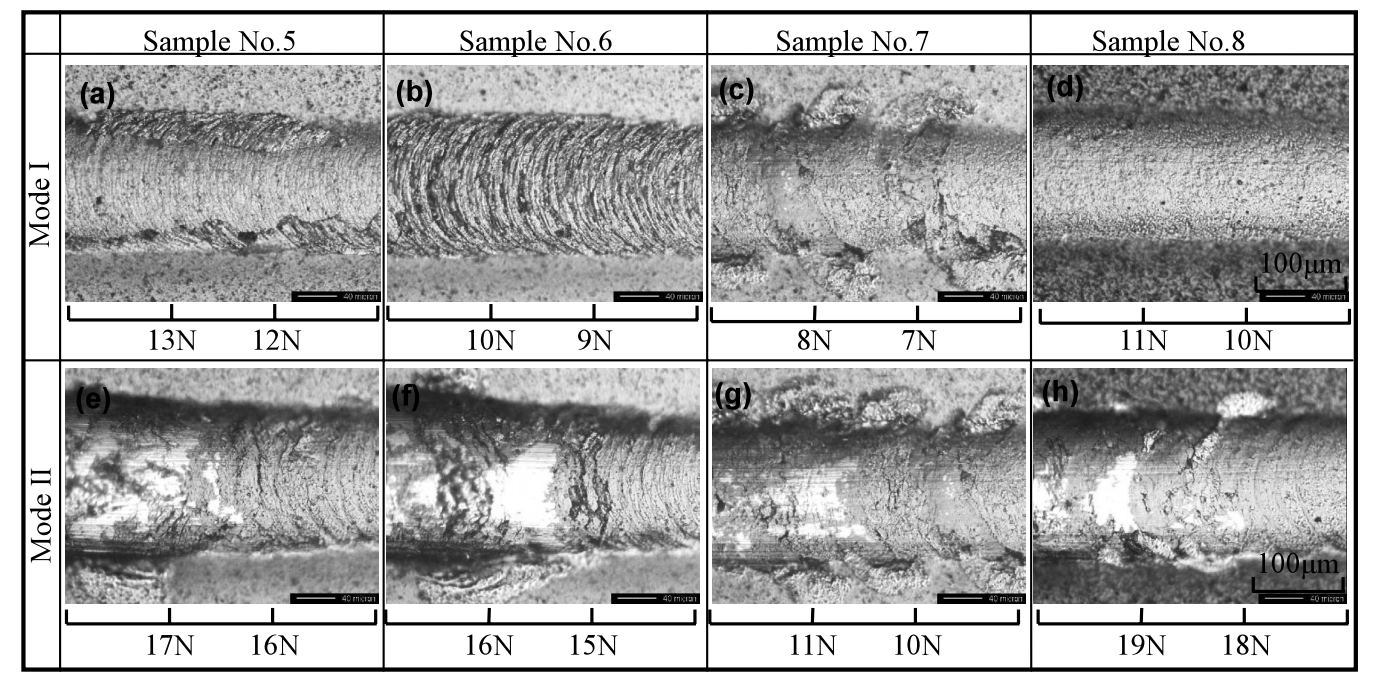

Fig. 3 Optical microscopy images of scratch tracks for multilayered coatings 


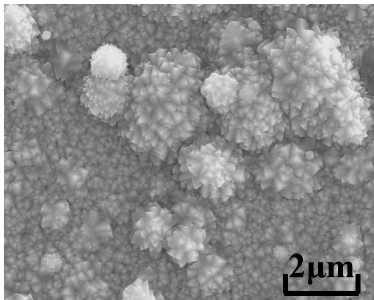

$R_{\mathrm{a}}=0.270 \mu \mathrm{m}$

(a) Sample No. 1

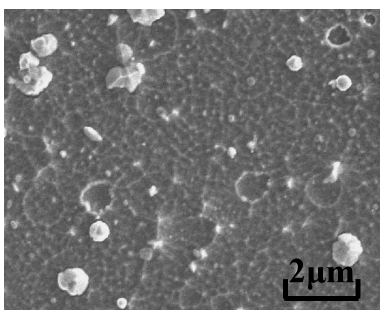

$R_{\mathrm{a}}=0.240 \mu \mathrm{m}$

(e) Sample No. 5

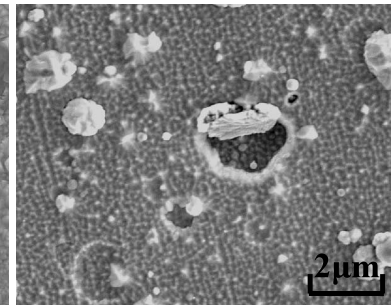

$R_{\mathrm{a}}=0.256 \mu \mathrm{m}$

(b) Sample No. 2

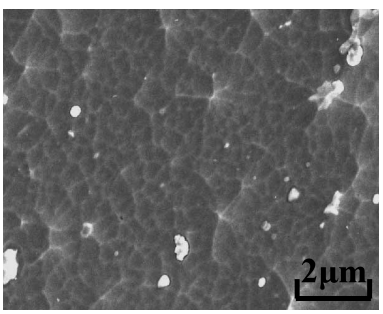

$R_{\mathrm{a}}=0.229 \mu \mathrm{m}$

(f) Sample No. 6

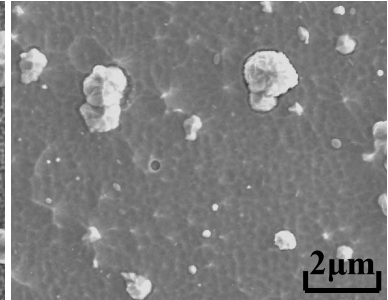

$R_{\mathrm{a}}=0.252 \mu \mathrm{m}$

(c) Sample No. 3

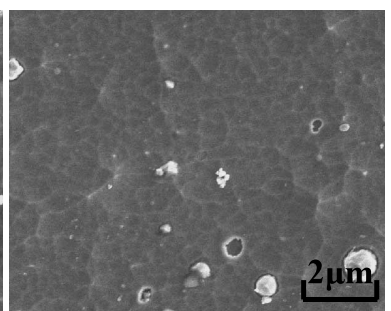

$R_{\mathrm{a}}=0.225 \mu \mathrm{m}$

(g) Sample No. 7

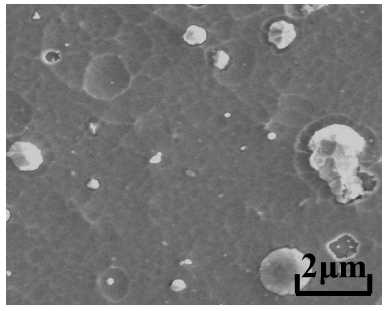

$R_{\mathrm{a}}=0.245 \mu \mathrm{m}$

(d) Sample No. 4

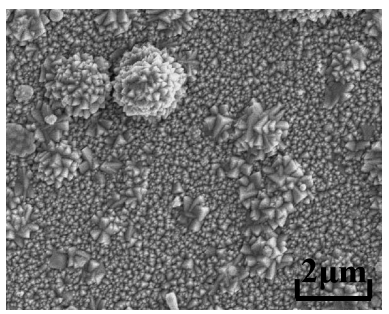

$R_{\mathrm{a}}=0.243 \mu \mathrm{m}$

(h) Sample No. 8

Fig. 4 SEM images of $\mathrm{CrN}$ surface coated by various bias voltage; (a) - (d) are for singlelayered coatings, (e) $-(\mathrm{h})$ are for multilayered coatings

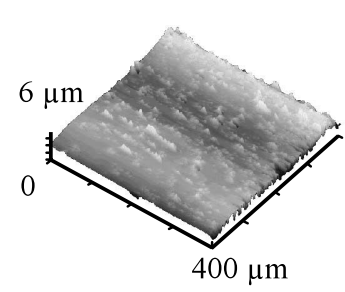

(a) $0 \mathrm{~V}$

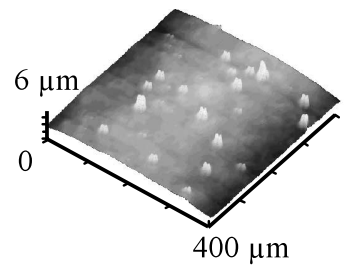

(b) $-20 \mathrm{~V}$

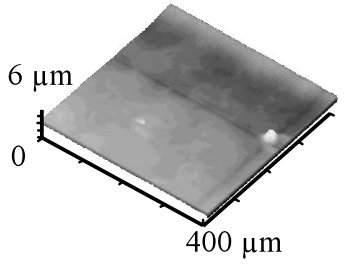

(c) $-40 \mathrm{~V}$

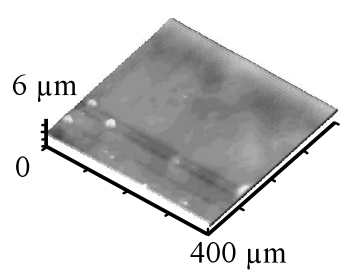

(d) $-60 \mathrm{~V}$

Fig. 5 Surface morphology of single-layered CrN surface observed by AFM

roughness values. Figure $4(a)-(d)$ are for the singlelayered surface and Fig. 4 (e) - (h) are for the multilayered surface. The film surfaces of sample Nos. 3 and 4 are smooth and few droplets of white spherical particles are observed, as shown in Fig. 4 (c) and (d). In contrast, when bias voltage decreases, many droplets are observed on the film surface, as shown in Fig. 4 (a) and (b). In particular, the film surface of $0 \mathrm{~V}$ is always covered by small particles with sharp edges (Fig. 4(a)). The surface roughness $R_{a}$ tends to increase with decreasing bias voltage, this would be caused by the difference in droplet distribution. AFM observation was performed on the single-layered films. The AFM observation results are shown in Fig. 5. It is obvious that the $\mathrm{CrN}$ films coated under the bias voltages of $40 \mathrm{~V}$ and $60 \mathrm{~V}$ have smooth surfaces and only a few particles are observed on the film surfaces. Thus, the bias voltage strongly affects the nanosized surface morphology of the film even though the difference in surface roughness is small.

3.2.2 Multilayered coatings For multilayered coatings, the film surface morphology depends on the bias voltage of the top layer. When the bias voltage of the top layer increases, the film surface becomes smooth. However, the influence of bias voltage on surface roughness is smaller than that in the case of a single layer.

\subsection{Hardness and Young's modulus}

The hardness and Young's modulus of the $\mathrm{CrN}$ film were measured using a dynamic ultra-microhardness tester. These results were obtained by averaging 20 points. Figures 6 and 7 show the dynamic hardness and Young's modulus of single- and multilayered coatings, respectively. In the case of single-layered coatings (Nos. 1-4), dynamic hardness increases with bias voltage. The dynamic hardness for bias voltage of $-60 \mathrm{~V}$ is threefold that of $0 \mathrm{~V}$ bias voltage. In the case of multilayered coating (sample Nos. 5-8), surface hardness strongly depends on the top layer condition. For example, when the top layer is coated under $60 \mathrm{~V}$ (sample No.6), the dynamic hardness is the highest value, while sample No. 8 of which the top layer coating is $0 \mathrm{~V}$ has the lowest value. Dynamic hardness and surface morphology strongly depend on the bias voltage of the top layer. The dynamic hardness of multi- 
layered coatings is also influenced by the combination of bias voltages. Although sample Nos. 6 and 7 are coated under the same top layer condition $(60 \mathrm{~V})$, sample No. 7 , where the intermediate and bottom layers were coated under the low bias voltage of $30 \mathrm{~V}$ and $0 \mathrm{~V}$, has a lower hardness than sample No. 6 having interlayers coated under $40 \mathrm{~V}$ and $20 \mathrm{~V}$. These hardness properties results from the decreases in the hardness of the intermediate and bottom

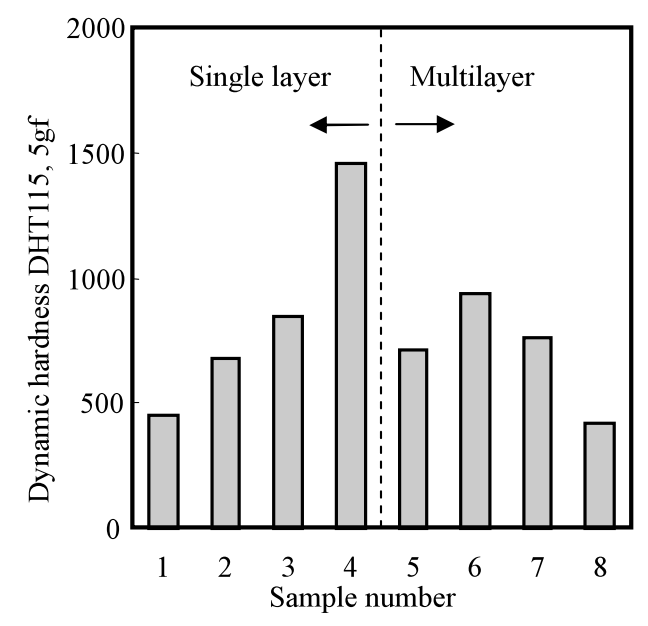

Fig. 6 Dynamic hardness data for coatings

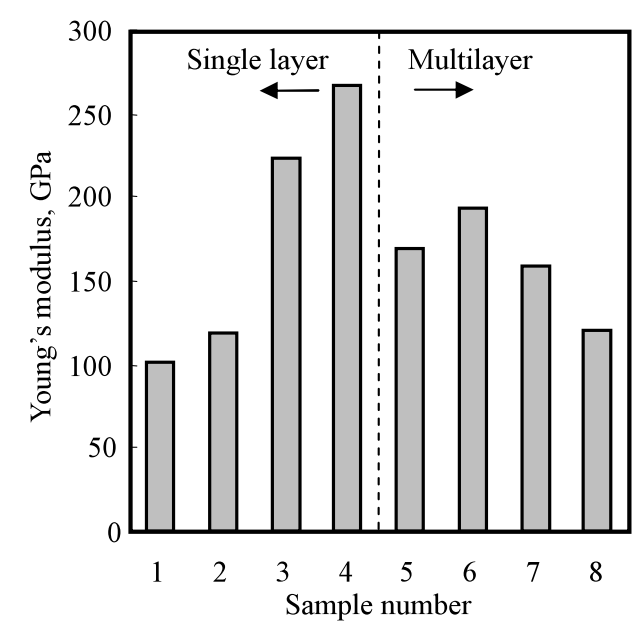

Fig. 7 Young's modulus data for coatings

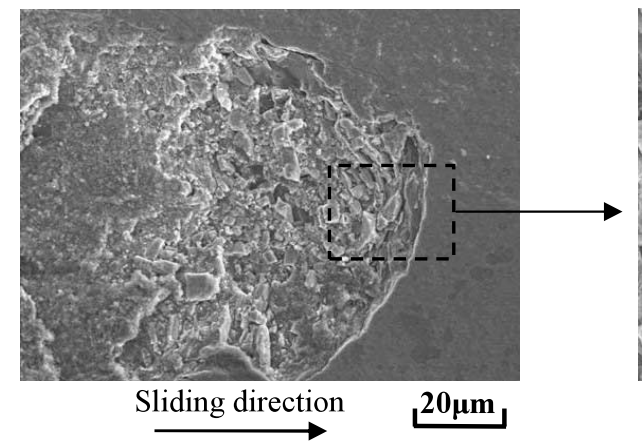

layers.

Young's modulus shows the same behavior as dynamic hardness. For single-layer coatings (sample Nos.1-4), a higher bias voltage coating exhibits a higher Young's modulus. For multilayer coatings (sample Nos. 5-8), Young's modulus depends on the combination of bias voltages.

\subsection{Tribological properties}

The pin-on-disk friction and wear test results are summarized in Table 2. Most of the samples were tested to $5000 \mathrm{~m}$ without delamination of the film. However, the tests of sample Nos. 3 and 4 were stopped at a sliding distance of less than $100 \mathrm{~m}$ because the macroscopic delamination of the films occurred, as shown in Fig. 8. For sample Nos. 3 and 4, the films were fractured brittlely and collapsed by the sliding contact of the ball. The shape of the delamination edge was semicircular and film delamination occurred along the sliding direction. It is considered that the film was deformed by normal load and then the film was broken by bending stress. It appears that the film fracture and delamination for sample Nos. 3 and 4 were related to their low critical load, as shown in Fig. 2. However, although the critical loads of sample No. 7 were lower than those of sample Nos. 3 and 4, the crack and delamination sample was not observed in the wear track of sample No. 7.

Sample Nos. 2 and 5-8 showed almost the same specific wear rate as the ball. Only for sample No. 1 was a high wear rate obtained. The specific wear rate for multilayered coating disks was influenced by the combination of bias voltages and the surface conditions of the top layer. In the case of multilayered disks, wear rate de-

Table 2 Specific wear rate of SUJ2 ball and CrN coating disk

\begin{tabular}{|c|c|c|c|c|c|c|c|c|}
\hline Sample No. & 1 & 2 & 3 & 4 & 5 & 6 & 7 & 8 \\
\hline $\begin{array}{l}\text { Coefficient of friction } \\
\text { during steady-state wear }\end{array}$ & 0.91 & 0.61 & - & - & 0.78 & 0.77 & 0.67 & 0.62 \\
\hline $\begin{array}{l}\text { Specific wear rate of ball, } \\
\times 10^{-5} \mathrm{~mm} 3 / \mathrm{m} \cdot \mathrm{N}\end{array}$ & 1.95 & 1.13 & - & - & 1.36 & 1.35 & 1.00 & 1.05 \\
\hline $\begin{array}{l}\text { Specific wear rate of disk (calculated } \\
\text { by mass loss), } \mathrm{x} 10^{-5} \mathrm{mg} / \mathrm{m} \cdot \mathrm{N}\end{array}$ & 0.24 & 0.60 & - & - & 0.60 & 0.34 & 0.54 & 0.78 \\
\hline
\end{tabular}

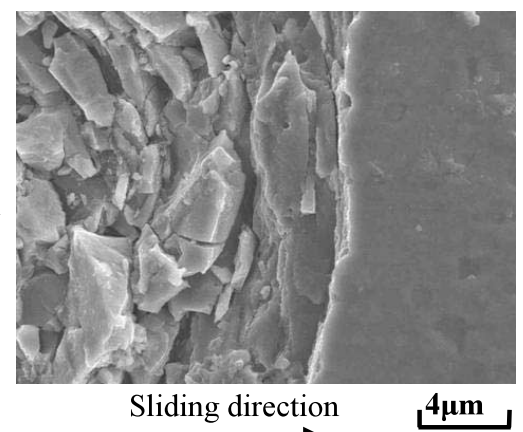

Fig. 8 SEM images of fractured CrN film in wear test (sample No.3, sliding distance: $100 \mathrm{~m}$ ) 
creased when the top layer was deposited under a high bias voltage (sample Nos. 6 and 7). However, for the singlelayered coatings, wear rate increased with bias voltage.

\section{Discussion}

\section{1 Influence of bias voltage on scratch behavior}

As shown in Fig. 2, it is clear from the scratch test data that bias voltage strongly influences the critical loads of the single-layered coatings. High-bias-voltage deposition results in a decrease in critical load. Dynamic hardness and Young's modulus are also affected by bias voltage, as shown in Figs. 6 and 7. Therefore, it is considered that the critical loads depend on the dynamic hardness and Young's modulus of $\mathrm{CrN}$ film. Figure 9 shows the relationship between dynamic hardness and critical load for single-layered coatings. Both $\mathrm{L}_{\mathrm{CI}}$ and $\mathrm{L}_{\mathrm{CII}}$ are markedly reduced to $6.6 \mathrm{~N}$ and $14.2 \mathrm{~N}$, respectively, when dynamic hardness increases. When the dynamic hardness DH is over 800 , these values hardly depend on dynamic hardness. Figure 10 shows the relationship between critical load and Young's modulus for single-layered coatings. The critical loads of $\mathrm{L}_{\mathrm{CI}}$ and $\mathrm{L}_{\mathrm{CII}}$ values decrease with increasing Young's modulus.

\subsection{Influence of multilayered coatings on scratch behavior}

The CrN films of sample Nos. 5 and 6 were coated under the same combination of bias voltages of 20, 40 and $60 \mathrm{~V}$ but under different deposition orders. The top layer of sample No. 5 was coated at $20 \mathrm{~V}$. That of sample No. 6 was coated at $60 \mathrm{~V}$. $\mathrm{L}_{\mathrm{CI}}$ is slightly higher for sample No. 5 than for sample No. 6. $\mathrm{L}_{\mathrm{CII}}$ value is also higher for sample No. 6 than for sample No. 5, as shown in Fig. 2. Sample Nos. 7 and 8 were coated under the same combination of bias voltages of 60, 30 and $0 \mathrm{~V}$. As shown in Fig. 2, there is a difference in critical load between sample Nos. 7 and 8. $\mathrm{L}_{\mathrm{CI}}$ and $\mathrm{L}_{\mathrm{CII}}$ values are clearly higher for sample No. 8 than for sample No. 7. These result from the coating con-

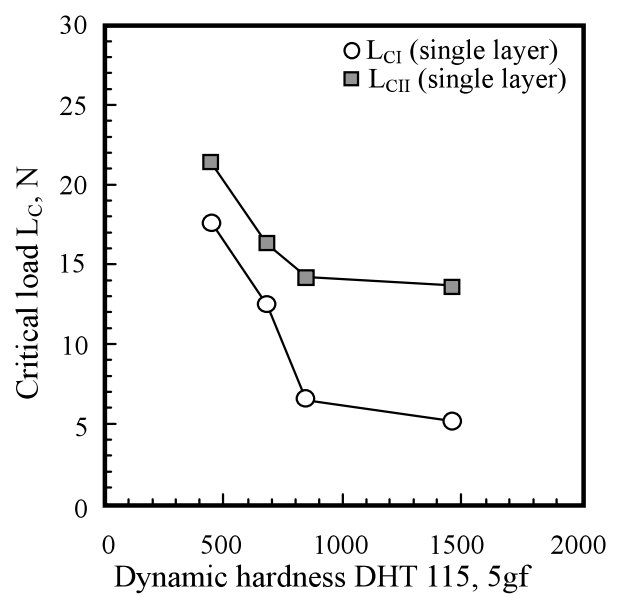

Fig. 9 Relationship between hardness and critical load for single-layered coating ditions of the top layer because the top layer of sample No. 7 was coated under $60 \mathrm{~V}$ and the top layer of No. 8 sample was coated under $0 \mathrm{~V}$. It appears that the combinations of bias voltages such as 20,40 and $60 \mathrm{~V}$ and 0 , 30 and $60 \mathrm{~V}$ result in the difference in mechanical properties between each layer. Figures 11 and 12 show the relationship between critical load and dynamic hardness, and the relationship between critical load and Young's modulus, respectively. It is clear from Figs. 11 and 12 that $\mathrm{L}_{\mathrm{CI}}$ decreases with increasing dynamic hardness and Young's modulus, regardless of the combination of bias voltage. However, the relationship between $\mathrm{L}_{\mathrm{CII}}$ and dynamic hardness or Young's modulus differs with respect to the coating combination. For sample Nos. 7 and 8, $\mathrm{L}_{\mathrm{CII}}$ decreases with increasing the dynamic hardness and Young's modulus. While, for sample Nos. 5 and 6 that value slightly increases with increasing dynamic hardness and Young's modulus. It appears that though the top layer coated under $0 \mathrm{~V}$ decreases the dynamic hardness and Young's modulus, the top layer contributes to the increase in $\mathrm{L}_{\mathrm{CII}}$ value. The critical load of sample No. 7 is lower than those of

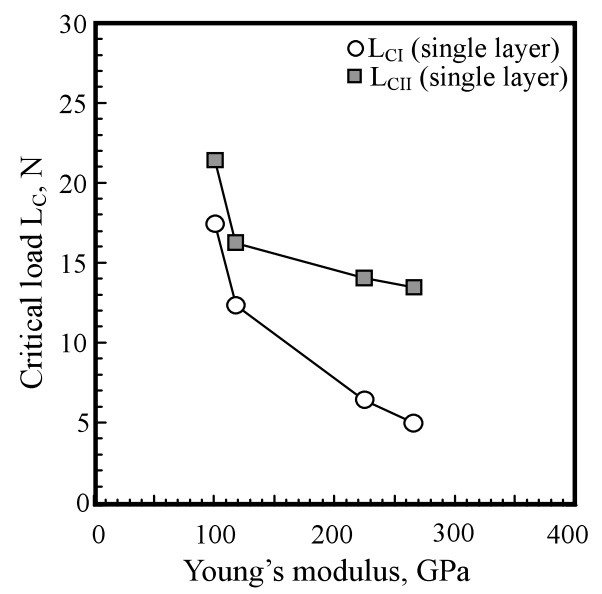

Fig. 10 Relationship between Young's modulus and critical load for single-layered coating

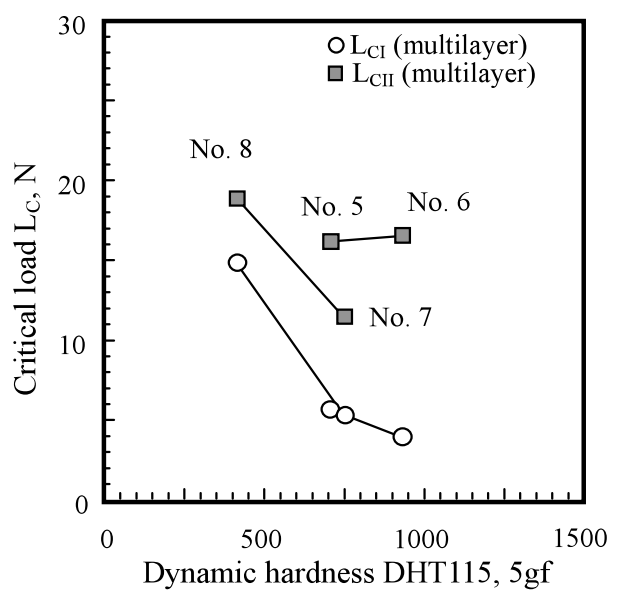

Fig. 11 Relationship between hardness and critical load for multilayered coating 


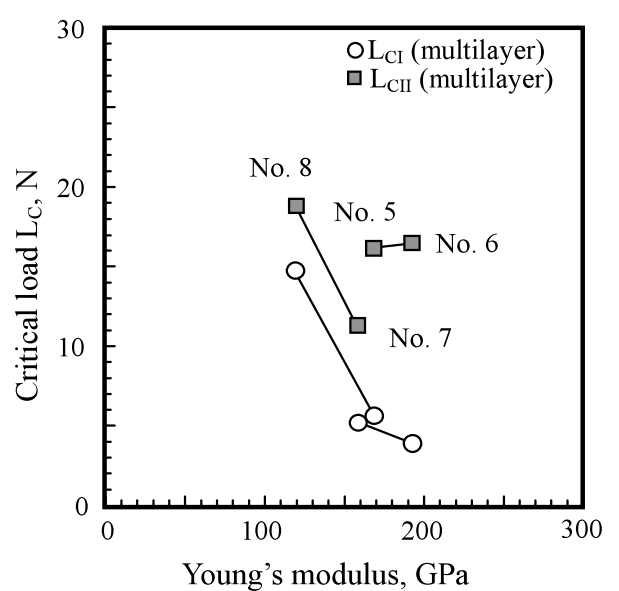

Fig. 12 Relationship between Young's modulus and critical load for multilayered coating

Nos. 5 and 6, as shown in Figs. 2, 11 and 12. For sample No. 7, large delamination of film was not observed during the pin-on-disk wear test. This fact suggests that if the brittle top layer would be broken and delaminated by the sliding contact, the ductile bottom layer coated under a bias voltage of $0 \mathrm{~V}$ may endure the complete delamination of film.

\section{Conclusions}

Scratch tests and pin-on-disk wear tests were performed to clarify the cracking and delaminating properties of $\mathrm{CrN}$ coatings. The $\mathrm{CrN}$ film was coated onto an aluminum alloy substrate by the arc ion plating method. The obtained results can be summarized as follows.

(1) The $\mathrm{L}_{\mathrm{CI}}$ of the single-layered coatings decreased with increasing bias voltage. The critical load at the partial delamination, $\mathrm{L}_{\mathrm{CII}}$, also decreased with increasing bias voltage. $\mathrm{L}_{\mathrm{CI}}$ and $\mathrm{L}_{\mathrm{CII}}$ did not improve by multilayered deposition, but the influence of the combination of bias voltages clearly appeared for critical loads.

(2) In the case of single-layered coatings, the dynamic hardness and Young's modulus of the $\mathrm{CrN}$ film increased with increasing bias voltage. In the case of multilayered coatings, the roughness, hardness and Young's modulus were strongly affected by the properties of the top layer and were also influenced by the deposition order.

( 3 ) Both $\mathrm{L}_{\mathrm{CI}}$ and $\mathrm{L}_{\mathrm{CII}}$ of the single layered coatings markedly decreased with increasing dynamic hardness. The correlation of Young's modulus with critical load was similar to the case of the dynamic hardness.

(4) The surface hardness and Young's modulus of the multilayered coatings have a strong influence on $\mathrm{L}_{\mathrm{CI}}$ regardless of the combination of bias voltages. $\mathrm{L}_{\mathrm{CII}}$ was influenced by the mechanical properties of the top layer and the combination of each layer.

(5) Although the critical loads of $40 \mathrm{~V}$ and $60 \mathrm{~V}$ single-layered coatings were higher than those of multilayered coatings with $60 \mathrm{~V}$ top, $30 \mathrm{~V}$ intermediate and $0 \mathrm{~V}$ bottom layers, large delamination occurred for singlelayered coatings during the pin-on-disk tribological test. The top layer could be broken and delaminated by the sliding contact, because of its brittle property. However, since the bottom layer was coated under $0 \mathrm{~V}$, the bottom layer might have ductility and flexibility and might endure the complete delamination of film.

\section{References}

( 1 ) Maejima, M., Saruwatari, K. and Takaya, M., Friction Behaviour of Anodic Oxide Film on Aluminum Impregnated with Molybdenum Sulfide Compounds, Surf. Coat. Technol., Vol.132 (2000), pp.105-110.

( 2 ) Zhao, Y., Chen, M., Liu, W., Liu, X. and Xue, Q., Preparation and Self-Lubrication Treatment of Ordered Porous Anodic Alumina Film, Materials Chemistry and Physics, Vol.82 (2003), pp.370-374.

( 3 ) Su, Y.L. and Lin, J.S., An Investigation of the Tribological Potential of TiN, CrN and TiN + CrN Physical Vapor Deposited Coatings in Machine Element Applications, Wear, Vol.170 (1993), pp.45-53.

( 4 ) Gahlin, R., Bromark, M., Hedenqvist, P., Hogmark, S. and Hakansson, G., Properties of $\mathrm{TiN}$ and $\mathrm{CrN}$ Coatings Deposited at Low Temperature Using Reactive Arc-Evaporation, Surf. Coat. Technol., Vol.76-77 (1995), pp.174-180.

( 5 ) Lai, F.D. and Wu, J.K., High Temperature and Corrosion Properties of Cathodic-Arc-Plasma-Deposited CrN Coatings, Surf. Coat. Technol., Vol.64 (1994), pp.53-57.

( 6 ) Hones, P., Consiglio, R., Randall, N. and Levy, F., Mechanical Properties of Hard Chromium Tungsten Nitride Coatings, Surf. Coat. Technol., Vol.125 (2000), pp.179-184.

( 7 ) Milosev, I., Abels, J.M., Strehblow, H.H., Navinsek, B. and MetikosHukovic, M., High Temperature Oxidation of Thin CrN Coatings Deposited on Steel, J. Vac. Sci. Technol. A, Vol.14 (1996), pp.2527-2534.

( 8 ) Navinsek, B. and Panjan, P., Oxidation Resistance of PVD Cr, Cr-N and Cr-N-O Hard Coatings, Surf. Coat. Technol., Vol.59 (1993), pp.244-248.

( 9 ) Bull, S.J. and Rickerby, D.S., Compositional, Microstructural and Morphological Effects on the Mechanical and Tribological Properties of Chromium Nitrogen Films, Surf. Coat. Technol., Vol.43-44 (1990), pp.732-744.

(10) Martinez, E., Romero, J., Lousa, A., Esteve, J., Lousa, A. and Esteve, J., Wear Behavior of Nanometric CrN/Cr Multilayers, Surf. Coat. Technol., Vol.163-164 (2003), pp.571-577.

(11) Lee, Y.-Z. and Jeong, K.-H., Wear-Life Diagram of TiN-Coated Steels, Wear, Vol.217 (1998), pp.175-181.

(12) Imbeni, V., Martini, C., Lanzoni, E., Poli, G. and Hutchings, I.M., Tribological Behaviour of MultiLayered PVD Nitride Coatings, Wear, Vol.251 (2001), pp.997-1002. 